\title{
EDUCATIONAL INITIATIVES TO DEVELOP TRANSVERSAL SKILLS IN THE MANAGEMENT SUBJECT OF MASTER'S DEGREE IN INDUSTRIAL ENGINEERING AT UNIVERSITAT POLITÉCNICA DE VALÉNCIA
}

\author{
Mónica Martínez-Gómez ${ }^{\mathbf{1}}$, José Jabaloyes, \& Andrea Conchado Peiró \\ Centre for Quality and Change Management, Universitat Politècnica de València, València, València,
} (Spain)

\begin{abstract}
This work presents an improvement of the structure and methodology of a subject entitled Management, belonging to the Master's Degree in Industrial Engineering (ETSII) at the Universitat Politècnica de València (UPV). The presented subject deals with the basic and fundamental aspects that the student will need in order to correctly perform the functions of business management in changing and competitive markets and environments and contributes to the formation of professionals capable of carrying out management, direction and evaluation tasks in productive organizations. From the subject, the students' management skills are strengthened to elaborate and build strategic alternatives of decision, both in relation to the understanding of the problems, as well as in the decision making and in the evaluation of the consequences that the own actions can have for the company and for the people. It is centered on the improvement of professional skills. In this context, UPV transversal competences (TC), aim to synthesize a competence profile acquired by all UPV graduates. This study comes from an Institutional Educational Innovation and Improvement Projects to develop a methodological coordination through webs of support in ETSII CT (PIME/19-20/151). The main goal of this project was to make easier our students to acquire the more complex CTs-UPV with an effective model that does not place an additional burden on instructors, providing students with e-learning resources such as support for their training.

This study is focused in CT04.-Innovation, Creativity and Entrepreneurship. Innovation is shown as a key competence for companies to remain competitive in the market. Innovation is based on creativity, knowledge and organization, understood as a way of working to achieve objectives. A new trend in higher education is the current shift towards improving innovation, creativity and entrepreneurship of students.

To work on these skills, students of Management have to do different exercises in groups where there are 4 to 6 randomly selected students with different roles. Each working group will start by creating a company, on which the different tools and methodologies will be developed through practical cases to achieve innovative and creative solutions that add value to the main stakeholders.

The achievement of the proposed techniques for developing Innovation, Creativity and Entrepreneurship competency has been revealed as a significant aspect for the students, and the web CTs-UPV designed on the project (https://ctetsii.blogs.upv.es) has been considered as a strong support for their achievement.
\end{abstract}

Keywords: Transversal skills, web ETSII transversal competencies, innovation competency, group dynamics.

\section{Introduction}

In the context of the European Higher Education Area (EHEA) it is necessary to guarantee that at the end of the degree the different competences have been achieved, the specific skills of the subjects studied of each degree and the acquisition of another skills, so-called transversal competences. The institutional project of Transversal Competence of the Universitat Politècnica de València (TC-UPV) carries out a classification in 13 competences (TC) were defined and introduced within all the curricula: Understanding and integration (TC1), Application practical thinking (TC-2), Analysis and problem solving (TC-3), Innovation, creativity and entrepreneurship (TC-4), Project design (TC-5), Teamwork and leadership (TC-6), Professional and ethical responsibility (TC-7), Effective communication (TC-8), Critical thinking (TC-9), Knowledge of contemporary issues (TC-10), Continuous learning (TC-11), Planning and time management (TC-12), and Instrumental specific (TC-13). 
The UPV, at this time in which the adaptation to learning environments different from the usual ones due to the COVID19 pandemic, has gained special relevance, and always in its commitment to seek synergies of all institutional actions that are being carried out in relation to the improvement of the teaching-learning process initiated the 2018-19 academic year a joint plan of educational innovation, under the name of "Learning and Teaching" (A+D).

The School of Industrial Engineering (ETSII) through the Teaching Innovation project PIME/19-20/151 has designed an e-learning platform, with the aim to make easier the acquisition of these skills by students. The goal of this platform is to bring students closer to these competences as you can see in Figure 1.

Figure 1.

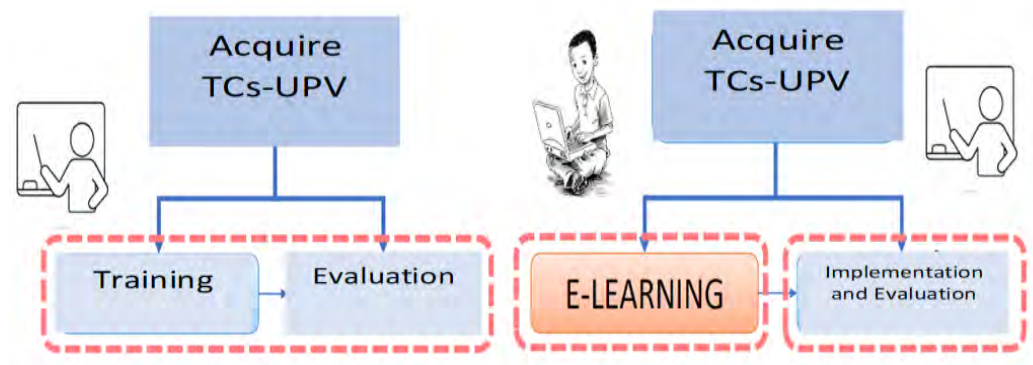

Source: Presentation of Institutional PYMES ETSII. Transversal Competences

The main objective of this work is to analyze if the level of CT-04, Innovation, creativity and entrepreneurship has increased after the students have used the platform.

This paper is structured as follows. Section two describes a review of the innovation competency. The third section presents the methodological framework for the design and implementation of this competence in the platform. Finally, the main results and conclusion are presented.

\section{Innovation competence}

Currently, one of the prerequisites required by companies is that professionals improve their qualifications in soft skills. The innovation competency appears as a source of competitive advantage in the business world. Innovation has become a relevant factor for the achievement of a competitive suitable advantage of companies in the market. The innovation competency can be considered as a cluster of different capacities and skills. However, it is not easy to define innovation, since it implies the acquisition of different capabilities and capacities among which the following are noteworthy: creativity, creative problem-solving, problem identification, independent thinking, be open to new ideas, focus on research, team work, forward-looking approach, among others and which have been discussed in different papers (Kairisto-Mertanen \& Mertanen, 2012; Marin-Garcia et al., 2011; Marin-Garcia et al., 2012, Martinez-Gomez, 2017 and Penttilä \& Kairisto-Mertanen, 2012 ). Innovation is a complex process that comprises several competencies, such as, perception of opportunities, ideas generation and evaluation, action plans, cooperation and risk. It is one of the most competitive advantage in determining the success or failure of a company in the global market, and nowadays is considered a as the magical recipe for all of today's problems in companies. In this context, we can define innovation as a presentation of the novelty (an idea, procedure, device, invention or process) or improvement of something that exists and adds value, and is useful for organizations. In order to improve organizational or group performance, innovation begins with generating ideas and finishes with implementing and using them (Marin-Garcia, Perez-Peñalver, \& Watts, 2013; Perello-Marin, Marin-Garcia, \& Marcos- Cuevas, 2013; Ramirez Bayarri, Marin-Garcia, \& Atares-Huerta, 2016).

A new trend in higher education is the current shift towards improving innovation, creativity and entrepreneurship of students. To build innovation competency, companies must include innovation in their competency models. Innovation represents the strategic process for competitiveness. In this context it has become an essential condition to know the expectations and needs of the customers. Many companies have opted to place the customer at the center of their business strategy as a formula to offer him what he demands and thus obtain better results.

A program of change towards innovation begins by defining what is of value to the customer, which will allow many innovative strategies to be generated, as can be seen in the Excellence Model for Innovation Management (EMOI) shown in Figure 2, which is based on the continuous improvement cycle or Deming cycle (PDCA). The first of the four stages covered by the EMOI model is fundamental for the success of its implementation and is the one that basically very few organizations develop. It basically consists of knowing the expectations and needs of customers and, therefore, understanding the purpose of 
the organization and its environment. The need to know the customer arises from the phrase "the world needs empathy" and that is what we will try to teach the students: how to empathize with their customers which contribute to increase their innovation competence.

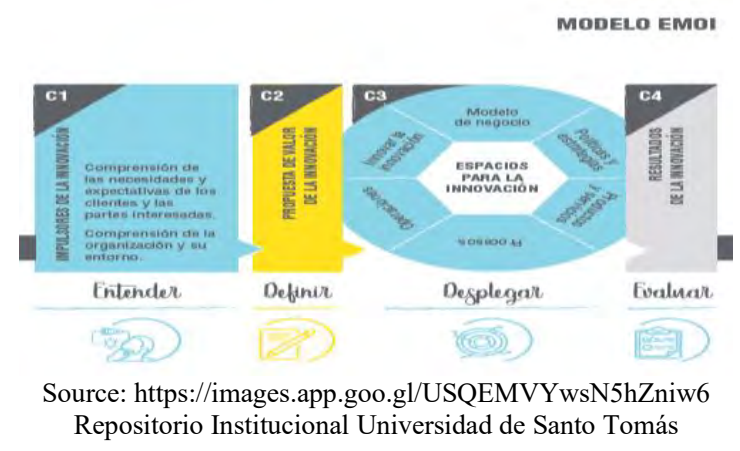

\section{Methodology}

To design the e-learning platform, the 6 transversal competencies that students recognized that they had more difficulties in acquiring were chosen: CT-4, CT6, CT-7, CT-10, CT-11 and CT12. The teachers who participated in the project focused on one of the competencies they had to evaluate in their subject and their contribution was to create an educational video explaining the methodology or activity they were going to work on to enhance it. With all the material, the ETSII TCs web page was created and can be accessed at https://www.etsii.upv.es/competencias/index-es.php.

At the beginning of the subject, the professors encourage the students to enter the page and consult the contents. In order, to check the usefulness of this tool, a survey was created by the Institute of Education Sciences. The survey was given to the students at the beginning and at the end of the course, to evaluate the level of knowledge of the students in the competence before and after visualizing its contents. The complete questionnaire is available upon request from the authors.

In our case we evaluated the competence CT-04 and the sample consisted of 72 students of the subject Business Management (BM), belonging to the Official Master's Degree in Industrial Engineering. As it was an online survey, only 30 students answered.

The Innovation Competences questions in the survey are showed in table 1.

Table 1. Items of Survey Innovation Competence.

Items of Survey Innovation Competence

1. I critically analyze the concepts and theories presented in the subjects.

2. In certain subjects, once I have studied them in depth, I am able to contribute personal ideas and justify them.

3. When a theory, interpretation or conclusion is presented in class or in books, I try to see if there are good arguments to support it.

4. I look for alternatives and original solutions to problems that are different from those usually used.

5. I am able to question the given things and when faced with a problem or challenge I try to identify aspects that can be improved or opportunities that can be taken advantage of.

6. I am able to use some creativity strategy and/or technique to generate ideas/solutions and represent them in a way that is understood.

7. I try to integrate knowledge I have acquired in different subjects to generate new ideas or proposals.

8. Before implementing an idea or solution, I analyze in depth the expected results to evaluate the value of the solution and draw conclusions.

9. To carry out an improvement or innovation, I plan in detail an action plan with its tasks and phases and I execute and control them.

10. Faced with a problem, to carry out an improvement or innovation, I plan in detail an action plan and execute its phases.

Once the data has been obtained, we proceeded with the statistical analysis. 


\section{Results}

The main descriptive statistics are shown in the Table 2, and for better understanding means are represented in Figure 3.

Table 2. Descriptive statistics of items of survey innovation competence.

\begin{tabular}{|c|c|c|c|c|c|c|c|c|}
\hline \multirow[t]{2}{*}{ Survey } & \multicolumn{4}{|c|}{ Pre } & \multicolumn{4}{|c|}{ Post } \\
\hline & Mean & $\begin{array}{l}\text { Standard } \\
\text { Deviation }\end{array}$ & Min & Max & Mean & $\begin{array}{l}\text { Standard } \\
\text { Deviation }\end{array}$ & Min & Max \\
\hline I critically analyze & 5,00 & 0,00 & 5,00 & 5,00 & 5,00 & 0,00 & 5,00 & 5,00 \\
\hline In certain subjects, & 4,17 & 0,83 & 3,00 & 5,00 & 4,37 & 0,49 & 4,00 & 5,00 \\
\hline When a theory, & 3,93 & 0,94 & 3,00 & 5,00 & 4,03 & 0,81 & 3,00 & 5,00 \\
\hline I look for alternatives & 3,00 & 1,34 & 1,00 & 5,00 & 4,00 & 0,00 & 4,00 & 4,00 \\
\hline I am able to question & 3,07 & 1,01 & 2,00 & 5,00 & 4,43 & 0,90 & 3,00 & 5,00 \\
\hline $\begin{array}{l}\text { I am able to use } \\
\text { some creativity }\end{array}$ & 3,93 & 0,58 & 3,00 & 5,00 & 4,33 & 0,48 & 4,00 & 5,00 \\
\hline I try to integrate & 3,80 & 0,66 & 3,00 & 5,00 & 4,07 & 0,83 & 3,00 & 5,00 \\
\hline Before implementing & 4,00 & 0,74 & 3,00 & 5,00 & 4,67 & 0,48 & 4,00 & 5,00 \\
\hline $\begin{array}{l}\text { To carry out an } \\
\text { improvement or i }\end{array}$ & 3,80 & 0,85 & 3,00 & 5,00 & 3,73 & 0,52 & 3,00 & 5,00 \\
\hline $\begin{array}{l}\text { Faced with a } \\
\text { problem }\end{array}$ & 3,37 & 0,85 & 2,00 & 5,00 & 3,90 & 0,48 & 3,00 & 5,00 \\
\hline
\end{tabular}

Figure 3. Means of items.

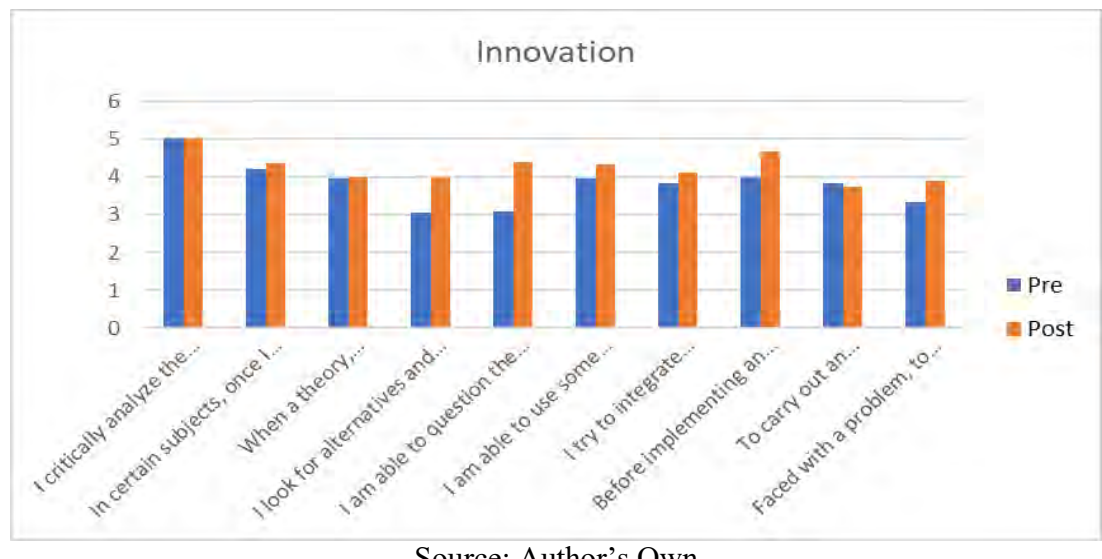

Source: Author's Own

As we can appreciate in Figure 3, except in the first and ninth items (I critically analyze the concepts and theories presented in the subjects and To carry out an improvement or innovation, I plan in detail an action plan with its tasks and phases and I execute and control them), students claimed to have improved their performance after working with the e-learning platform. To regard if there were indeed significant differences, an ANOVA was performed. Results are showed in Table 3 and we can notice that in many of the items the difference are significance.

Table 3.

\begin{tabular}{lrrrrr}
\hline & Sum of Squares & df & Mean of Scare & $\mathrm{F}$ & P-value \\
\hline In certain subjects, once I have &, 600 & 1 &, 600 & 1,283 &, 262 \\
When a theory, interpretation &, 150 & 1 &, 150 &, 194 &, 661 \\
I look for alternatives and orig & 15,000 & 1 & 15,000 & 16,731 &, $000^{* *}$ \\
I am able to question the given & 28,017 & 1 & 28,017 & 30,525 &, $000^{* *}$ \\
I am able to use some creativity & 2,400 & 1 & 2,400 & 8,419 &, $005^{* *}$ \\
I try to integrate knowledge I h & 1,067 & 1 & 1,067 & 1,894 &, 174 \\
Before implementing an idea o & 6,667 & 1 & 6,667 & 17,059 &, $000^{* *}$ \\
To carry out an improvement &, 067 & 1 &, 067 &, 135 &, 715 \\
Faced with a problem, to carry & 4,267 & 1 & 4,267 & 8,945 &, 004 \\
\hline
\end{tabular}

Note: F-tests are post-hoc, based on assigning cases to groups to minimize within-group and maximize between group distances. ** Significant lever al $5 \%$ 


\section{Conclusions}

This work has allowed to contextualize the process of development and acquisition of transversal competencies through an e-learning platform and places its development beyond the scope of a subject. All this has been applied to the transversal competence related to Innovation, a framework that can be extended to the rest of the transversal competences.

\section{Acknowledgements}

This work has been developed within the research project called "Methodological coordination through support websites in ETSII Degrees for CT04.-Innovation, Creativity and Entrepreneurship and CT07.-Ethical, environmental and professional responsibility." (Ref. PIME/19-20/151) funded by the Vice-Rectorate for Studies, Quality and Accreditation at Universitat Politècnica de València

\section{References}

Acuña, P. V. (2016). La innovación como proceso y su gestión en la organización: una aplicación para el sector gráfico colombiano. Suma de Negocios, 7(16), 125-140. doi: https://doi.org/10.1016/j.sumneg.2016.02.007

Guzman, LM (2019) aplicación del modelo emoi y la herramienta mpdca para la innovación en las empresas colombianas. Ensayo de grado presentado. Universidad Militar Nueva Granada. retrieved from https://repository.unimilitar.edu.co/bitstream/handle/10654/35804/GuzmanGuzmanLuis Miguel2019.pdf? sequence $=1$

Marin-Garcia, J. A., Aznar-Mas, L. E. \& González-Ladrón de Gevara, F. (2011). Innovation types and talent management for innovation. Working Papers on Operations Management, vol 2, no 2, pp. 25-31.

Marin-Garcia, J., Andreu Andres, M., Atares-Huerta, L., Aznar-Mas, L., Garcia-Carbonell, A., González-Ladrón- de-Gevara, F., Montero Fleta, B., Perez-Peñalver, M., \& Watts, F. (2016). Proposal of a Framework for Innovation Competencies Development and Assessment (FINCODA). WPOM-Working Papers on Operations Management, 7(2), 119-12 6.

Marin-Garcia J.A., Pérez-Peñalver, M.J., Vidal-Carreras, PI. \& Maheut, J. (2012). How to assess the innovation competency of higher education students. Proceedings of the 7 th International Conference on Industrial Engineering and Industrial Management, p.p. 920-928. 2012.

Marin-Garcia, J. A., Perez-Peñalver, M. J., \& Watts, F. (2013). How to assess innovation competence in services: The case of university students. Direccion y Organizacion (50), 48-62.

Martínez-Gómez, M; Marí-Benlloch, M \& Marin-Garcia, J.A. (2017). Validation of Incode Framework for Assessment of Innovation Competency of Higher Education Students: A Multidimensional Technique for Affinity Diagram to Detect the most Relevant Behaviors and Skills". Modeling Human Behavior: Individuals and Organizations. Nova Science Publishers, Inc. pp. 25-36. 2017.

Penttilä, T. \& Kairisto-Mertanene, L. (2012) Innovation competence barometer ICB: a tool for assessing students' innovation competences as learning outcomes in higher education, Proceedings of INTED2012 Conference. pp. 6347-6351.

Perello-Marin, M. R.; Marin-Garcia, J. A. \& Marcos-Cuevas, J. (2013). Towards a Path Dependence Approach to Study Management Innovation. Management Decision 51(5), 1037-1046.

Ramírez Bayarri, L.; Marín García, JA.; Atarés Huerta, LM. (2016). ¿Cómo se ha evaluado la competencia de innovación en las empresas y las universidades?. Working Papers on Operations Management. 7(2):140-167. https://doi.org/10.4995/wpom.v7i2.6886

Universidad Politécnica de Valencia (UPV). (2020) Herramientas de metaplanificación. https://poliformat.upv.es/access/content/group/CFP_69392_27242/Material\%20Docente\%20Asign aturas/Asignatura $\% 202 . \% 20$ Herramientas $\% 20 \mathrm{de} \% \overline{2} 0$ metaplanificacion.pdf

Universidad Politécnica de Valencia (UPV). (2020) Herramientas de metaplanificación. https://poliformat.upv.es/access/content/group/CFP_69392_27242/Material\%20Docente\%20Asign aturas/Asignatura $\% 202 . \% 20$ Herramientas $\% 20 \mathrm{de} \% \overline{2} 0$ metaplanificacion.pdf 